\title{
Synchronous Cultures of Acanthamoeba castellanii and Their Use in the Study of Encystation
}

\author{
By ABDUL H. CHAGLA AND ALAN J. GRIFFITHS \\ Microbiology Department, University College, Cardiff CF1 $1 X P$
}

(Received 12 April 1978)

\begin{abstract}
A selection technique based on low-speed centrifugation of an exponentially growing culture and a starvation induction method for obtaining synchronous cultures of Acanthamoeba castellanii were compared. The selection method gave the highest levels of division and synchrony. Amoebae which were induced to encyst at different times during the growth cycle by the addition of $\mathrm{MgCl}_{2}$ to the cultures differed in their ability to initiate encystation, indicating that there may be a relationship between the position of a cell in the growth cycle and its competence to initiate differentiation. The patterns of protein and ribose synthesis which were observed during synchronous growth indicate that the changes which occur in the levels of these materials during encystation may not be unique to the differentiation process.
\end{abstract}

\section{INTRODUCTION}

One of the main advantages of synchronous cultures of microbes and other cell types is that relatively large quantities of cells can be obtained for biochemical analysis (Mitchison, 1971). Some techniques for synchronizing division of Acanthamoeba cultures have been described. These include induction methods employing temperature shifts (Neff \& Neff, 1964), inhibitors of mitosis (Band et al., 1970) or nutrient limitation (Band \& Mohrlock, 1973) and a selection method based on the separation of the smallest cells from an exponentially growing culture by continuous-flow centrifugation (Lloyd et al., 1975). Although induction methods are undoubtedly useful for some purposes, their validity in biochemical investigations is generally open to question due to the inevitable physiological disturbance caused to the cells during the induction process. It is for this reason that selection methods have been developed. The selection technique which has previously been used with Acanthamoeba was devised to produce large-scale cultures but for some purposes, such as the study of the behaviour of whole cells, smaller culture volumes are adequate. One problem which requires the use of such cultures of Acanthamoeba arises in the study of encystation since it is still far from clear whether the encystation process is initiated in response to inhibition of cell division (Byers et al., 1969; Neff \& Neff, 1972; Chagla \& Griffiths, 1974). This paper compares a selection technique based on low-speed centrifugation and a starvation induction method for obtaining synchronous cultures of Acanthamoeba castellanii and examines the encystation responses of amoebae at different times during the growth-division cycle.

\section{METHODS}

The organism and its culture. Cultures of Acanthamoeba castellanii (Neff strain) were grown in PGY medium (Chagla \& Griffiths, 1974). Batch cultures $(50 \mathrm{ml})$ were inoculated with $5 \mathrm{ml}$ of an exponentially growing culture and incubated in $250 \mathrm{ml}$ conical flasks at $30^{\circ} \mathrm{C}$ in a shaking water-bath. 


\section{Table 1. Synchrony of Acanthamoeba castellanii cultures induced by starvation}

Exponentially growing cultures $\left(24\right.$ and $48 \mathrm{~h}$ ) were starved in $50 \mathrm{~mm}-\mathrm{MgCl}_{2}$ for 2.5 or $4.0 \mathrm{~h}$ and then returned to fresh growth medium. All cultures were incubated in a shaking water-bath at $30{ }^{\circ} \mathrm{C}$. The lag was measured as the period from the time when the amoebae were returned to growth medium to the initiation of division.

$\begin{array}{ccccc}\begin{array}{c}\text { Time }(\mathrm{h}) \\ \text { of } \\ \text { starvation }\end{array} & \begin{array}{c}\text { Age (h) of } \\ \text { culture when } \\ \text { starved }\end{array} & N / N_{0} & \begin{array}{c}\text { Synchrony } \\ \text { index, }\end{array} & \begin{array}{c}\text { Length of } \\ \text { lag (h) }\end{array} \\ 2.5 & 24 & 1.29 & F & 2 \cdot 0 \\ 2.5 & 48 & 1.91 & 0.43 & 3.5 \\ 4.0 & 24 & 1.76 & 0.74 & 2.5 \\ 4.0 & 48 & 1.92 & 0.50 & 1.5\end{array}$

* The synchrony index was not measurable following this treatment.

Selection procedure for obtaining synchronous cultures. Batch cultures were transferred to $50 \mathrm{ml}$ 'Corex' centrifuge tubes and centrifuged $\left(10 \mathrm{~g}, 4 \mathrm{~min} ; r_{\mathrm{av}} .10 \mathrm{~cm}\right)$ in an MSE bench centrifuge, fitted with a swing-out head, at room temperature. The resulting supernatant contained about $10 \%$ of the original amoeba population. This was carefully decanted to a sterile $250 \mathrm{ml}$ conical flask and incubated at $30^{\circ} \mathrm{C}$ in a shaking water-bath.

Starvation induction of synchrony. Amoebae from 24 and $48 \mathrm{~h}$ batch cultures were collected by centrifuging $\left(1000 \mathrm{~g}, 10 \mathrm{~min} ; r_{\text {av }}, 10 \mathrm{~cm}\right)$ in a bench centrifuge at room temperature. These cells were suspended in a starvation medium consisting of $50 \mathrm{~mm}-\mathrm{MgCl}_{2}$ and incubated for 2.5 or $4.0 \mathrm{~h}$; the cells were then recovered by centrifugation and resuspended in fresh growth medium.

Cell counts. Amoebae were counted, without prior fixation, in a Fuchs-Rosenthal haemocytometer (Weber \& Sons, Lancing, Sussex). A minimum of 400 cells was counted for each sample.

Assessment of synchrony. The effectiveness of the synchronizing procedures were assessed using the synchrony index $(F)$ of Blumenthal \& Zahler (1962) in which

$$
F=\left(N / N_{0}\right)-2^{t / g}
$$

where $N$ is the number of amoebae after division has occurred, $N_{0}$ is the initial number of amoebae, $t$ is the time taken to divide and $g$ is the generation time. In these experiments, a generation time of $8.75 \mathrm{~h}$, obtained from measurements of growth in batch cultures, was used in the calculation of $F$. Using this formula, cultures exhibiting perfectly synchronous growth will have a synchrony index of $1 \cdot 00$.

Measurements of protein and $R N A$. The chemical fractionation used prior to the measurement of protein and RNA has been described previously (Griffiths \& Hughes, 1969). Protein was measured in a fraction which was insoluble in trichloroacetic acid but soluble in alkali, and RNA was measured as ribose in a fraction soluble in hot trichloroacetic acid.

Induction of encystation. Amoebae in synchronous cultures were induced to encyst by adding $\mathrm{MgCl}_{\mathbf{2}}$ (final concentration $50 \mathrm{~mm}$ ) at intervals to individual cultures. The degree of encystation was estimated from differential counts of amoebae and cysts (Chagla \& Griffiths, 1974). Encysting cultures were also incubated at $30{ }^{\circ} \mathrm{C}$ in conical flasks on a shaking water-bath.

\section{RESULTS AND DISCUSSION}

\section{Synchrony induced by starvation}

A feature of these experiments was the relatively short lag period (compared with the lag exhibited by cultures synchronized by the selection method; Fig. 1a) before division was initiated (Table 1). This indicated that starvation was effective in bringing about an accumulation of the amoebae at a point preceding cell division. The $N / N_{0}$ values, which ranged from 1.29 to 1.92 , coupled with the low values of $F$ suggest that some of the cells were incapable of division when they were returned to the growth medium and may have begun to encyst. One of the treatments, which consisted of starving $24 \mathrm{~h}$ amoebae for $4 \mathrm{~h}$, gave a synchrony index of 0.74 which compared favourably with the values obtained in the selection synchrony experiments. The $N / N_{0}$ value was, however, one of the lowest obtained in all the experiments. 


\section{Table 2. Encystation induced at different times in synchronous cultures of Acanthamoeba castellanii prepared by the selection method}

Encystation was induced by the addition of $\mathrm{MgCl}_{2}$ (final concentration $50 \mathrm{~mm}$ ) to synchronous cultures. Percentage encystation was estimated from differential counts of cysts and amoebae after incubation in PGY/Mg medium for the times shown.

Time (h) at which encystation was induced

0

3

6

9
Encystation (\%) after incubation in $\mathrm{PGY} / \mathrm{Mg}$ for:

$\begin{array}{cccc}30 \mathrm{~h} & 40 \mathrm{~h} & 50 \mathrm{~h} & 55 \mathrm{~h} \\ 23 & 31 & 41 & 50 \\ 21 & 26 & 33 & 39 \\ 18 & 22 & 28 & 36 \\ 21 & 27 & 33 & 39\end{array}$

\section{Selection synchrony}

A typical growth curve of a culture synchronized by the selection method is shown in Fig. $1(a)$. In 10 experiments using the low-speed centrifugation procedure the synchrony indices ranged from 0.59 to 0.74 with a mean of 0.67 and standard deviation of 0.04 . The $N / N_{0}$ values ranged from 1.92 to 2.00 (mean 1.97 ; S.D. 0.02 ). In some cases, although an apparently perfect doubling of the cell population occurred, the synchrony indices were lower than in cultures with inferior division levels. This is accounted for by the longer times required to accomplish division in these cultures. This may indicate that there is no strict relationship between cell size and age in $A$. castellanii or may simply be due to differing efficiencies of the centrifugation process in selecting homogeneous age-classes of amoebae. The synchrony indices do, however, compare favourably with those exhibited by $A$. castellanii and other protists in synchronous cultures prepared by continuous-flow centrifugation (Lloyd et al., 1975).

\section{Encystation responses of amoebae in synchronous cultures}

Amoebae which had been induced to encyst by the addition of $\mathrm{MgCl}_{2}$ to a culture at $0 \mathrm{~h}$ consistently showed higher levels of encystment than amoebae induced at other times in the cell cycle (Table 2). It appears that up to the point at which division is initiated (about $6 \mathrm{~h}$ ) the encystment responses of the cells decrease with increasing cell age. At $9 \mathrm{~h}$, when the amoebae have essentially entered a second cycle of growth, the levels of encystment are again higher. Thus, there may be a relationship between the position of a cell in the cellcycle and its competence to initiate the differentiation process of encystation. The use of a marker of the earlier stages of encystation, which would give greater sensitivity in the detection of the initiation phase of the differentiation, would make a valuable contribution to the resolution of this problem.

\section{Changes in the chemical composition of amoebae during synchronous growth}

In view of the evidence which shows that significant changes in such cell components as protein and RNA occur during the normal cell-cycle (Mitchison, 1971), it is by no means certain that the reports of similar changes during cyst formation in Acanthamoeba (Byers et al., 1969; Chagla \& Griffiths, 1974; Griffiths \& Hughes, 1969) are necessarily a unique feature of the differentiation process. During synchronous growth of $A$. castellanii, there was a linear increase in the protein content of the cultures throughout the cell-cycle, producing a doubling in the level after about $6 \mathrm{~h}$ (Fig. $1 b$ ). The accumulation of ribose exhibited a slightly different pattern. After an initial phase, when ribose increased linearly, the rate of accumulation declined at a point corresponding to the initiation of division and then increased again (Fig. 1c). When the results were calculated on the basis of units per cell, 


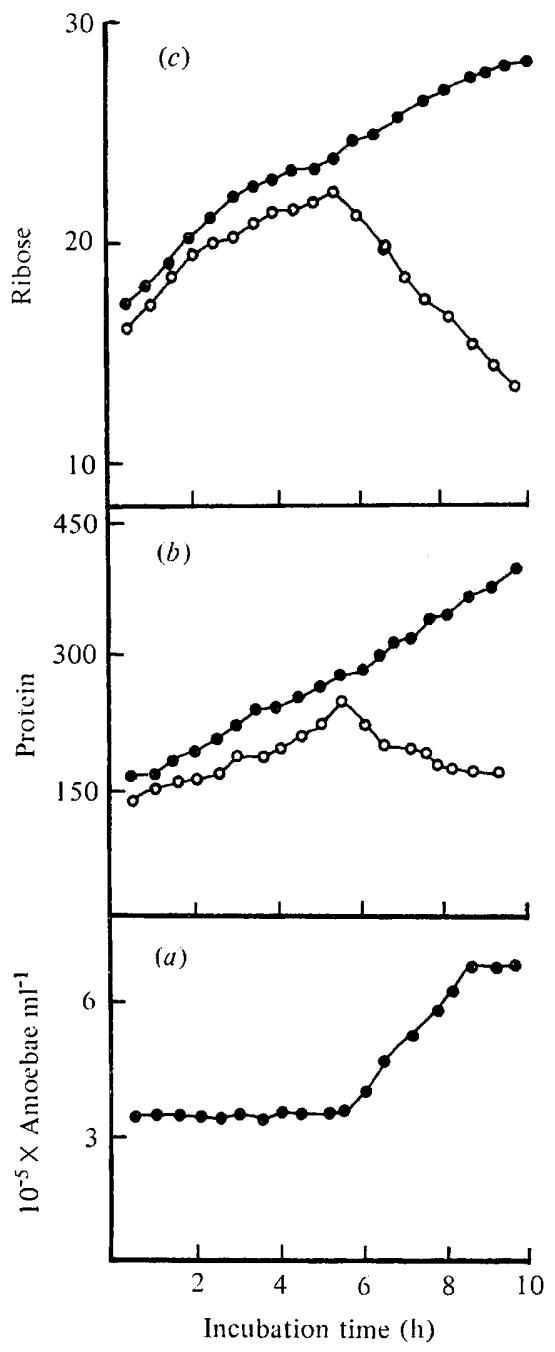

Fig. 1. Changes in the levels of protein and ribose in Acanthamoeba castellanii during synchronous growth. Synchronous cultures were prepared by the selection method. (a) Growth curve: the value of $F$ in this culture was $0 \cdot 74$. (b) Protein content:,$\mu \mathrm{g}(\mathrm{ml} \text { culture })^{-1} ; \bigcirc, 3 \times \mu \mathrm{g}\left(10^{5} \text { cells }\right)^{-1}$. (c) Ribose content: $0, \mu \mathrm{g}$ ( $\mathrm{ml}$ culture $)^{-1} ; \bigcirc, \mu \mathrm{g}\left(10^{5} \text { cells }\right)^{-1}$.

however, the ribose and protein contents were seen to decrease rapidly at the onset of division. Clearly, profound changes in the chemical composition of $A$. castellanii occur during the normal processes of growth and the dramatic changes in the levels of protein and ribose which have been reported in encysting cells may not be a unique feature of the differentiation. Similar changes have been described in other microbes during differentiation and are usually ascribed to the major processes of structural reorganization which often occur and are thought to be 'triggered' by those environmental factors which also initiate the differentiation. From the evidence presented here, at least some of these changes may only be normal cell-cycle events which appear magnified in the absence of net cell growth. 


\section{REFERENCES}

BAND, R. N. \& Mohrlock, S. (1973). The cell cycle and induced amitosis in Acanthamoeba. Journal of Protozoology 20, 645-657.

BAND, R. N., MOHRlock, S. \& Rubin, R. W. (1970). Separate induction of amitotic and mitotic division in Acanthamoeba rhysodes. Nature, London 227, 379-381.

Blumenthal, L. K. \& Zahler, S. A. (1962). Index for measurement of synchronization of cell populations. Science 135, 724.

Byers, T. J., Rudick, V. L. \& Rudick, M. J. (1969). Cell size, macromolecule composition, nuclear number, oxygen consumption and cyst formation during two growth phases in unagitated cultures of Acanthamoeba castellanii. Journal of Protozoology 16, 693-699.

Chagla, A. H. \& Griffiths, A. J. (1974). Growth and encystation of Acanthamoeba castellanii. Journal of General Microbiology 85, 139-145.
Griffiths, A. J. \& Hughes, D. E. (1969). The physiology of encystment of Hartmannella castellanii. Journal of Protozoology 16, 93-99.

Lloyd, D., John, L. Edwards, C. \& Chagla, A. H. (1975). Synchronous cultures of micro-organisms: large-scale preparation by continuous-flow size selection. Journal of General Microbiology 88, 153-158.

Mrtchison, J. M. (1971). The Biology of the Cell Cycle. Cambridge: Cambridge University Press.

NefF, R. J. \& NefF, R. H. (1964). Induction of synchronous division in amoebae. In Synchrony in Cell Division and Growth, pp. 213-246. Edited by E. Zeuthen. New York: Wiley Interscience.

NEFF, R. J. \& NEFF, R. H. (1972). Induction of differentiation in Acanthamoeba by inhibitors. Comptes rendus des travaux du Laboratoire Carlsberg 39, 112-168. 